\title{
AccountingBusiness Transactions; Accounting Equation; Types of Accounts
}

\author{
${ }^{1}$ Ali Ehtesham, ${ }^{2}$ Aghdasjafarimotlagh \\ 'department of accounting,Saveh branch,Islamic Azad University, Saveh, Iran \\ ${ }^{2}$ Masters Accounting Student, Saveh branch,Islamic Azad University, Saveh, Iran
}

\begin{abstract}
Accounting is often called, and rightly so, the language of business. It is so because the purpose of accounting is to inform by way of financial statements the results of business operations as well as the various assets and liabilities. Accounting facilitates the preparation and presentation of information to the users for making diverse types of decisions. Accounting statements and reports are needed by various groups such as shareholders, creditors, potential investors, columnists of newspapers, proprietors, suppliers, creditors, bankers and others. Apart, credit rating agencies and various research organisations including governmental agencies require accounting information to compile data, analytical reports, etc.

In this article, an humble attempt has been made to explain (i) what is the business transaction, (ii)

What is the Accounting Equation and (iii) What are the different types of accounts. Methodology is simple: the material is taken from books on Accounting. Examples have been given with solutions for helping the students/readers to understand the topics fully.
\end{abstract}

\section{Introduction}

As stated above, Accounting can be understood as the language of financial decisions. It is not one-shot activity; accounting is an ongoing process of performance-measurement and reporting the results to the various groups of decision-makers who are called users of information-value. The information has to possess the qualitative characteristics such as relevance of its value, reliability of the information, comparability of the information-value, verifiability, timeliness of reporting/information, and understandability.

\section{Current Literature Survey}

Literature relating to Accounting information characteristics mentioned above is reproduced:

IASB Financial Reporting was kick-started in 2001 with its main objective to helping IASB to introduce or revise accounting standards for international integration of Accounting practices.

\section{Relevance:}

Alan Melville ( $3^{\text {rd }}$ edition),in his published book, stated that 'Relevance' (of information value to users) is the attribute of being useful in taking investment-decisions - making or continuing investment in an entity; information is relevant when it has predictive value - it assists users of information derived from the financial statements for evaluating what risks/dangers are in store not only that existed in the past but also those arising currently and might spring up surprises in the time to come; the information either confirms or revises users' previous assessments. For this, apart from faithful presentation, there has to be complete and objective depiction of economic phenomenon.

Reliability:

Faithful presentation of data in financial statements lends it credibility and reliability, especially when these are audited. Mautz and Sharaf (1961, p.42) said that financial data should be verifiable. If not, there would be no place for auditing; it cannot exist as verification and valuation are the two basic functions of audit. If no such assumption is entertained, we do away with auditing as a subject. He adds that "verifiable' does not mean "beyond all doubt' as, according to him, auditors do not say on corporate economy, efficiency and effectiveness in their audit reports; they confine their reports to verification of valuation and documents supporting transactions. Users of information want expect reliable information on corporate economy, efficiency and effectiveness for taking decisions. In view of what Lee \& Tweed say, based on empirical evidence (1977 and $1981)$, it is problematic situation to make information relevant to the users.

Afaanz (2010), in his published article, stated that accuracy, credibility and concreteness of information is the foundational value of reliability concept. Contextual changes have been taking place in the world due to process of globalisation. Traditional approach is still followed for identification and measurement of intangible 
assets; value relevance of intangibles has been generally exaggerated. The value relevance is conditional upon reliability of information.

\section{Comparability:}

Alan Melville ( $3^{\text {rd }}$ edition), in his published book, stated that comparability is aboutfollowing a standard or practice brings about comparability which helps users for proper and scientific appraisal of risk and forecast results like future earnings. It leads to following same policies and practices everywhere and by all entities, thereby ensuring comparability (not uniformity) as goal of financial information. Users can identify similarities and dissimilarities in accounting reports.

\section{Verifiability:}

Alan Melville ( $3^{\text {rd }}$ edition), in his published book stated that verifiability is the quality which assures users of information that it faithfully represents the phenomenon; it ensures general consensus (not unanimity) among different knowledgeable and independent observers. It also ensures correct information representation and use of appropriate unbiased and error-free recognition/measurement method for evaluation.

Dr. Andrew Higson, in his letter dated October 1, 2008 to FASB (File reference 1570 - 100) after reproducing meaning from 'Oxford English Dictionary' and quoting Lee (1993) as that the notion of verification in financial reporting is very strong and there are explicit specifications of verifiability as a primary quality, expected of the financial information that is reported externally. He also quoted Mautz and Sharaf's tentative postulates of auditing $(1961$, p.42) that "Financial statements and financial data are verifiable".

\section{Timeliness:}

Alan Melville ( $3^{\text {rd }}$ edition), in his published book, said that right information in right quantity with right content/dimensions at the right time by the right source (dependable/authentic) is value-relevant for making investment/credit decisions. As such, Financial Statements are prepared at specified intervals and this periodicity kept unchanged.

\section{Understandability:}

Alan Melville ( $3^{\text {rd }}$ edition), in his published book, asserted that understanding helps in comprehending meaning. Comparability also enhances understandability of financial reporting. Precise, clear and understandable information, after statistical or mathematical treatment, gets value-added; but analytical ability and diligence of users is necessary for taking decisions.

Supplement to IFRS outlook issue 86 (Oct 2010) stated that the purpose of enhancing qualitative characteristics - comparability, reliability, timeliness, verifiability and understanding - is to ensure enhancement of valuerelevance, and faithfulness in presenting factual and relevant information in financial statements for users' benefits.

Accounting academics have forcefully advocated recognition of Intangible assets in financial statements. Evidence was provided to show that intangibles are value relevant (Francis and Schipper, 1999; Lev and Zerowin, 1999; Goodwin and Ahmed, 2006). They noticed that there was statistically significant relationship between information value of intangible assets and market value of companies.

\section{Business Transactions}

\section{Concepts}

Any economic transaction or event of a business which can be expressed in monetary terms should be recorded. Traditionally, accounting is a method of collecting, recording, classifying, summarizing, presenting and interpreting financial data of an economic activist. The series of business transactions occurs during the accounting period and its recording is referred to an accounting process is a complete sequence of accounting procedures which are repeated in the same order during each accounting period. Therefore, accounting process involves the following steps:

\section{i) Identification of Transaction:}

In accounting, only financial transactions are recorded. A financial transaction is an event which can be expressed in terms of money and which brings change in the financial position of a business enterprise. An event is an incident or a happening which may or may not bring any change in the financial position of a business enterprise. Therefore, all transaction are events but all events are not transactions. A transaction is a complete action, to an expected or possible future action. In every transaction, there is movement of value from one source to another. For example, when goods are purchased for cash, there is a movement of goods from the seller to the buyer and a movement of cash from buyer to the seller. Transactions may be external (between a 
business entity and a second party, e.g. goods sold on credit to Arshad or internal (which do not involve second party), e.g. depreciation charged on machinery. The following illustration will make understanding easier:

Illustration: State with reason whether the following events are transactions or not in the business house of Mr. Ashraf Wani, Proprietor, Super Computers.

(i) Mr. Ashraf Wani started business with capital (brought in cash ) Rs. 40,000/-

(ii) Paid salaries to staff Rs. 5,000.

(iii) Purchased machinery for Rs. 20,000 in cash.

(iv) Placed an order with Sheikh \& Co. for goods for Rs. 5,000.

(v) Opened a Bank account by depositing Rs. 4,000.

(vi) Received pass book from bank.

(vii) Appointed Shoab as Manager on a salary of Rs. 14,000 per month.

(viii) Received interest from bank Rs.1, 500 .

(ix) Received a price list fromShafi\& Brothers.

\section{Solution}

Here, each event is to be considered from the view point of Mr. Ashraf's business. Those events which will change the financial position of the business of Mr. Ashraf should be regarded as transactions.

(i) It is a transaction because it changes the financial position of Mr. Ashraf's business. Cash will increase by Rs. 40,000 and capital will increase by Rs. 40,000.

(ii) It is a transaction because it changes the financial position of Mr. Ashraf's business. Cash will decrease by Rs. 5,000 and Salaries (expenses) will increase by Rs. 5,000 .

(iii) It is a transaction because it changes the financial position of Mr. Ashraf's business. Machinery comes in and cash goes out.

(iv) It is not a transaction, because it does not change the financial position of the business.

(v) It is a transaction because it changes the financial position of the business. Bank balance will increase by Rs. 4,000 and cash balance will decrease by Rs. 4,000 .

(vi) It is also not a transaction because it does not change the financial position of Mr. Ashraf.

(vii) It is also not a transaction because it does not change the financial position of Mr. Ashraf.

(viii) It is a transaction because it changes the financial position of Mr. Ashraf's business.

(ix) It is not a transaction because it does not change the financial position of the business of Mr. Ashraf.

\section{ii) Recording the Transactions:}

Recording of transactions is done in Journal in the first instance.Journal is the first book of original entry in which all transactions are recorded event-wise and date-wise and presents a historical record of all monetary transactions. Journal may further be divided into sub-journals as well.

\section{iii) Classifying Business Transactions:}

Accounting is the art of classifying business transactions. Classification means statement setting out for a period where all the similar transactions relating to a person, a thing, expenses, or any other subject are grouped together under appropriate heads of accounts.

\section{iv) Summarizing Transactions:}

Summarizing is the art of making the activities of the business enterprise as classified in the ledger for the use of management or other user groups i.e. sundry debtors, sundry creditors etc. summarization helps in the preparation of Profit and Loss Account and Balance Sheet for a particular financial year.

\section{v) Analysis and Interpretation of Transactions:}

The financial information or data is recorded in the books of account must further be analyzed and interpreted so to draw meaning full conclusions. Thus, analysis of accounting information will help the management to assess in the performance of business operation and forming future plans also.

\section{vi) Presentation and reporting of financial information:}

The end users of accounting statements must be benefited from analysis and interpretation of data as some of them are the "shareholders" and other one the "stake holders". Comparison of past and present statements and reports, use of ratios and trend analysis are the different tools of analysis and interpretation. 
From the above discussion one can conclude that accounting is an art which starts and includes steps right from recoding of business transactions of monetary character to the communicating or reporting the results thereof to the various interested parties. For this purpose, the transactions are classified into various accounts, the description of which follows in the next section.

\section{B. ACCOUNTING EQUATION}

Dual concept states that 'for every debit, there is a credit'. Every transaction should have two-sided effect to the extent of same amount. This concept has resulted in a accounting equation which states that an an point of time assets of any entity must be equal (in monetary terms) to the total of owner's equity and outsider's liabilities. In other words, accounting equation is a statement of equality between the assets and the sources which finance the assets and is expressed as:

Assets $=$ Sources of Finance

Assets may be tangible e.g. land, building, plant, machinery, equipment, furniture, investments, cash, bank, stock, debtors etc. or intangible e.g. patent rights, trade marks, goodwill etc.

Sources include internal i.e. capital provided by the owner and external i.e. liabilities. Liabilities are the obligations of the business to others outsiders. The above equation gets expanded.

Assets $=$ Liabilities + Capital

All transactions explain the transaction of revenues, expenses, losses and gains, the equation can be expanded thus:

Assets + Expenses $=$ Liabilities + Revenue + Owner's equity

Or

Assets $=$ Liabilities $+($ Revenue - Expenses $)+$ Owner's equity

Or

Assets $=$ Liabilities + Owner's equity + Owner's equity

(Income) which ultimately becomes

Assets $=$ Liabilities + Owner's Equity

Let us consider the facts of the following case, step by step, to understand as to how the equation remains true event in changed circumstances.

\section{Illustration}

1) Commenced business with cash Rs. 50,000.

2) Purchased goods for cash Rs. 20,000 and on credit Rs. 30,000.

3) Sold goods for cash Rs. 40,000 costing Rs. 30,000.

4) Rent paid Rs. 500.

5) Bought furniture Rs. 5,000 on credit.

6) Bought refrigerator for personal use Rs. 5,000.

\section{Solution}

1) Business receives cash Rs. 50,000 (assets) and it owes Rs. 50,000 (Liability) to the proprietor as his capital contribution i.e. equity.
Assets (=)
Liabilities
$(+)$
Owner's Equity
Cash Rs. 50,000
Nil
Capital Rs. 50,000

2) Purchased goods for cash Rs. 20,000 and on credit Rs. 30,000. Business has acquired assets namely goods worth Rs. 50,000. Another asset (cash) has decreased by Rs. 20,000 while liability - creditors - have increased by Rs. 30,000 . 


\begin{tabular}{|lc|l|l|}
\hline Assets & $(=)$ & Liabilities $(+)$ & Owner's Equity \\
\hline Cash & 30,000 & Creditors 30,000 & Capital 50,000 \\
\hline Goods & 50,000 & & \\
\hline & 80,000 & 30,000 & 50,000 \\
\hline
\end{tabular}

3) Sold goods for cash Rs. 40,000 costing Rs. 30,000

This transaction has resulted in decrease of goods by Rs. 30,000 and increase in cash by Rs. 40,000 thus increasing equity by Rs. 10,000

\begin{tabular}{|lc|l|l|}
\hline Assets & $(=)$ & Liabilities $(+)$ & Owner's Equity \\
\hline Cash & 70,000 & Creditors 30,000 & Capital 60,000 \\
\hline Goods & 20,000 & & \\
\hline & 90,000 & 30,000 & 60,000 \\
\hline
\end{tabular}

4) Rent paid Rs. 500

This transaction has resulted in an expenditure of Rs. 500 effecting decrease of cash and equity by Rs. 500 each.

\begin{tabular}{|lc|l|c|}
\hline Assets & $(=)$ & Liabilities $(+)$ & Owner's Equity \\
\hline Cash & 69,500 & Creditors 30,000 & Capital 59,500 \\
\hline Goods & 20,000 & & \\
\hline & 89,500 & 30,000 & 59,500 \\
\hline
\end{tabular}

5) Bought furniture on credit Rs. 5,000

This transaction results in acquiring an asset namely furniture worth Rs. 5,000 and increasing creditors by Rs. 5,000

\begin{tabular}{|lr|l|l|}
\hline Assets & $(=)$ & Liabilities $(+)$ & Owner's Equity \\
\hline Cash & 69,500 & Creditors 35,000 & Capital 59,500 \\
\hline Goods & 20,000 & & \\
\hline Furniture & 5,000 & & \\
\hline & 94,500 & 35,000 & 59,500 \\
\hline
\end{tabular}

6) Bought refrigerator for personal use Rs. 5,000. This transaction will have the effect of reducing both cash as well as capital by Rs. 5,000 each.

\begin{tabular}{|lr|l|l|}
\hline Assets & $(=)$ & Liabilities $(+)$ & Owner's Equity \\
\hline Cash & 64,500 & Creditors 35,000 & Capital 54,500 \\
\hline Goods & 20,000 & & \\
\hline Furniture & 5,000 & & \\
\hline \multicolumn{2}{|c|}{89,500} & 35,000 & 54,500 \\
\hline
\end{tabular}

\section{TYPES OF ACCOUNTS}

Transactions are recorded in proper accounts. For this purpose, all accounts are categorised in groups maintaining homogeneity. These are described in the following paragraphs:

Account Defined: An account is a summary of the relevant transactions at one place relating to a particular head. It records not only the amount of transaction with its particulars (by way of a narration) but also their effect and direction.

\section{Classification of Accounts}

The classification of accounts is given below:

1) Personal Accounts: 
Accounts, which are related to individuals, firms, companies, co-operative societies, banks, financial institutions are known as personal accounts. All the personal accounts may further be classified into three categories.

(i) Natural Personal Accounts: Accounts of individuals (natural persons) such as Ashraf's A/c, Abdul's $\mathrm{A} / \mathrm{c}$ and Sheikh's A/c are natural personal accounts.

(ii) Artificial Personal Accounts: Accounts of firms, companies, and banks, financial institutions such as Rehman Chemical Industries Ltd., Rotary Club, M/s Shamim\& Sons, Dubai Citizens' Bank, and Saudi National College are artificial persons' accounts, created under provisions of law.

(iii) Representative Personal Accounts: The accounts recording transaction relating to limited expenses and income are classified as nominal accounts. But in certain cases (due to the matching concept of accounting) the amount on a particular date, is payable to the individuals or recoverable from individuals. Such amount (i) relates to the individuals or recoverable from individuals. Such amount (ii) relates to the particular head of expenditure or income and (iii) represents person to whom it is payable or from whom it is recoverable. Such accounts are classified as representative personal account e.g. Wages outstanding account, pre-paid insurance account, etc.

2) Real Accounts: Real accounts are the accounts related to assets or proprieties. These may be classified into tangible real accounts and intangible real accounts. The accounts relating to tangible assets (which can be touched, occupy space, purchased and sold) such as building, plant, machinery, cash, furniture, etc.; these are classified as tangible real accounts. Intangible real accounts (which do not have physical shape and can not be touched and occupy no space) are the accounts related to intangible asset such as goodwill, trademarks, copyrights, patents $-\mathrm{R} \& \mathrm{D}$ expenditure - etc.

3) Nominal Accounts: The accounts relating to income, expense, losses and gains are classified as nominal accounts. For example: Wages Account, Rent Account, Interest Account, Salary Account, Bad Debts Account, Purchase, Account, etc. fall in the category of nominal accounts (Abstract Accounts).

Accounting is better understood if rules of debit and credit are properly understood. I explain these below:

\section{Rules Of Debit And Credit}

Basically, debit means to enter an amount to the left side of an account and credit means to enter an amount to the right side of an account. In the abbreviated form Dr. stands for debit (or debtor) and Cr. stands for credit (or creditor). Both debit and credit (or debtor and creditor) may represent either increase or decrease in existing balance depending upon the nature of an account and business transaction.

The rules for Debit and Credit are given below:

\begin{tabular}{|l|l|l|}
\hline \multicolumn{1}{|c|}{ Types of Accounts } & \multicolumn{1}{c|}{ Rules of Debit } & \multicolumn{1}{c|}{ Rules for Credit } \\
\hline a) For Personal Accounts & Debit the receiver & Credit the giver \\
\hline b) For Real Accounts & Debit what comes in & Credit what goes out \\
\hline c) For Nominal Accounts & Debit all expenses and losses & Credit all incomes and gains \\
\hline
\end{tabular}

Illustration: Try to classify the following items into personal, real and nominal accounts.

(i)

(ii)

(iii)

(iv)

(v)

(vi)

(vii)

(viii)

(ix)

(x)

(xi)

(xii)

(xiii)

(xiv)
Investments

Freehold premises

Accrued Interest to Ram

Haryana Agro Industries Corporation

Janata Mechanical Works

Salary Accounts

Loose Tools Accounts

Purchases Account

Corporation Bank Ltd.

Capital Account

Brokerage Account

Tool Tax Account

Dividend Received Account

Royalty Account 


\section{(xv) Sales Account}

Solution to the above:

Real Accounts: (i), (ii) (vii), (viii), (xv)

Nominal Accounts: (vi, (xi), (xiii), (xiv)

Personal Accounts: (iii), (iv), (v), (ix), (x)

\section{Concluding Remarks}

Assets are recognised as such when there is expectation of future income by using them, otherwise such assets that do not promise future income are non-performing and removed from reporting in the financial statements. Liabilities are created by past transactions and repayable in the future. Intangible assets are either purchased (from external sources) or created internally. According to International Accounting Standard (IAS 38), all internally created intangibles are to be treated as expense as incurred - no capitalisation for them is permissible, except in circumstances where clear evidence is available regarding their future income flow to the entity. The externally created intangible assets (e. g. purchased goodwill, etc.) can be classified as Intangible assets for reporting in the financial statements provided future income-flow from them to the entity is expected.

Accounting practices, conventions and concepts help in correct reporting of business transactions and thereby the users of the information-value are benefited and they depend upon the information as the information is derived from the verifiable accounts and evidences on record; auditors certify the veracity of the information furnished in the financial statements published at regular intervals. The fact remains that the position disclosed is as on a certain date only and does not contain performance comments of the whole period.

\section{References}

[1] International Journal of Business and Management, www.ccsenet.org/ijbm Accounting Management by International Standard. JenoBeke

[2] JenoBeke, International Accounting Regulations Response for the Global Financial Crises

[3] Lennard Andrew, Stewardship and the Objectives of Financial statements: A Comment on IASB's Preliminary Views on an Improved Conceptual Framework for Financial Reporting : The Objective of Financial Reporting and Qualitative Characteristics of Decision Useful, Accounting for Europe, 2007, vol. 4 Issue 1, pp. 51-66,16p

[4] Mary E. Barth, Wayne R. Landsman and Mark H. Lang, International Accounting Standards and Accounting Quality, Journal of Accounting Research, Vol. 46, no. 3, June3, 2008

[5] Principles of Accounting, J. Ireland, 279002(2005)

[6] The Value Relevance and Reliability of Intangible Assets: Evidence from Australia before and after adopting IFRS

[7] The value relevance or reliability of Intangible assets, Evidence from Australia Before and Adopting IFRS (Dec 26,2012)

[8] Maheshwari, S. N ; Advanced Accountancy

[9] Gupta, R. L. ; Advanced Accountancy

[10] Shukla, M. C. and T. S. Grewal; Advanced Accounts 